Article

\title{
Preparation of SLS Polypropylene Powder by Solvent Method
}

\author{
Liang Fang ${ }^{1}$, Yan Wang1, and Yang $\mathrm{Xu}^{1}$ \\ 1 School of Material Science and Engineering, Wuhan Institute of Technology, Wuhan 430074, Hubei, China \\ * Correspondence: wangyan@wit.edu.cn; Tel.: +86-159-9426-3868
}

\begin{abstract}
The application of solvent method in the preparation of polypropylene powders was investigated, including the influence of various technological conditions, such as the raw material melt index of polypropylene, processing temperature, dosage of the solvent and the packing pressure. The experimental data show that using solvent method can effectively produce polypropylene powder, and the optimal technological conditions are: melt index of polypropylene being about $17.8 \mathrm{~g} / 10 \mathrm{~min}$, processing temperature being about $166.0{ }^{\circ} \mathrm{C}$, dosage of the solvent being about $0.067 \mathrm{~g} / \mathrm{ml}$ and the packing pressure being about $0.7 \mathrm{MPa}$.Under this technological conditions, polypropylene powder with excellent sphericity could be prepared, the apparent density of powder can reach $0.40 \mathrm{~g} / \mathrm{cm} 3$ and the prepared powder displayed a narrow size distribution with the mean size of about $42.7 \mu \mathrm{m}$.
\end{abstract}

Keywords: polypropylene powder; solvent method; selective laser sintering; 3D print

\section{Introduction}

Selective laser sintering (SLS) is a widespread additive manufacturing technology in which a three-dimensional object is created layer by layer from heat-fusible powdered materials with heat supplied from a moving laser beam[1-4]. Comparing with other additive manufacturing technologies, one of the main advantages associated with SLS is material versatility. The dominance of polymeric materials, relative to metals and ceramics, is their ease of processing at relatively modest temperatures. This permits lower laser energy to be employed by SLS than are required to directly sintering with metals and ceramics. Although in theory any polymer available in powder form can be processed by laser sintering, only a few polymer powders can be used for manufacturing parts with high mechanical properties, surface quality and accuracy[5-9]. According to viscous sintering mechanism, it is difficult to produce fully dense SLS parts from amorphous polymers because of the high viscosity above glass transition temperature. For crystalline polymers, the part bed temperature can be kept near melt point, that fully dense parts can be produced because the powders under the laser heating can be melted completely[10,11]. In SLS process, amorphous polymers like polycarbonate (PC) and polystyrene (PS),have been used to create models, patterns and parts for investment casting applications, while crystalline polymers, like polyamide, have been used to produce functional parts which have fully dense and good mechanical properties. Polyamide 12 (PA12) is certainly the most widely used laser sintering materials at the present time[12-13]. However, the price of PA12 powders is very high leading to the high SLS fabrication cost, so there is a need to develop a much cheaper polymer powders[14].

Polypropylene(PP) is the most common semi-crystalline polymer extensively applied in many fields due to its low cost and good material performance such as a relatively low density, superior mechanical properties, high temperature resistance, corrosion resistance, good electrical properties and chemical stability[15-17]. The aim of this paper is to investigate the production of laser sintering PP powders with appropriate particle size and spherical morphology. PP powders produced by cryogenic grinding show poor powder flowability, low packing density, unfavorable particle morphology and inappropriate particle size distributions[18-19]. This paper uses dissolutionprecipitation to produce PP powders. Dissolving PP in a suitable solvent at a high temperature, then 
by changing the temperature or adding second kinds of non-solvent PP will precipitate as powders[20-21]. By controlling suitable process conditions, nearly spherical PP particles with appropriate particle size could be prepared.

\section{Materials and Methods}

\subsection{Materials preparation}

Polypropylene resin (grades: SK3500, SD233CF, RP707CF, SA233CF, HJ730, T30S, eps30r) was used for the experiment. The solvent was xylene (containing $99.0 \%$ xylene, $0.1 \%$ benzene and $0.1 \%$ methylbenzene) which was obtained from Tianjin Fuyu Fine Chemical Co.,Ltd.(Tianjin,China).

The dissolution-precipitation procedure for the polypropylene powders was as flows. Polypropylene resin and a solvent were added to a 1-L high-pressure reactor. The oxygen was pumped out, and kept the pressures in the range of $0 \sim 1.1 \mathrm{MPa}$ by adding nitrogen. The mixture was stirred when the temperature reached $155^{\circ} \mathrm{C} \sim 185^{\circ} \mathrm{C}$ for $1 \mathrm{~h}$. Then, stirring was stopped and the mixture was cooled at the rate of $0.5^{\circ} \mathrm{C} / \mathrm{min}$ to $120^{\circ} \mathrm{C}$ until polypropylene began to precipitate. The temperature was maintained at $120^{\circ} \mathrm{C}$ until the precipitation was complete (within $30 \mathrm{~min}$ ), and when the temperature was cooled to room temperature, the products were removed, and the solvent was filtered.

\subsection{Morphological Analysis}

The melt index of different grades of polypropylene were determined with a FR-1811A melt flow indexer manufactured by Shanghai Ruifa Instrument Technology Co., Ltd.(Shanghai, People's Republic of China), according to the ASTM D1238-98 standards. The apparent density of polypropylene powders were tested with a XBM-100 apparent density analyzer constructed by Chengde Jingmi Testing Machine Co.,Ltd.(Chengde, People's Republic of China), according to the GB/T 1636-2008 and GB/1636 standards. The size distribution and mean diameter of the powders were measured with a Winner-2000 laser light scattering technique at room temperature, which was manufactured by Jinan Winner Particle Instruments Stock Co.,Ltd.(Jinan, People's Republic of China), according to the GB/T 19077.1-2008 standards. The spherical degree of the powders were observed with a XD-202 optical microscopy by Nanjing Jiangnan Novel Optics Co.,Ltd.(Nanjing, People's Republic of China). The morphologies of the powders were examined with a JSM5510LVscanning electron microscope at operating voltages below $20 \mathrm{KV}$.

\subsection{Thermal Analysis}

The melting and cooling behavior of polypropylene powders were studied with a Netzsch (Erich NETZSCH GmbH \& Co., Germany) 200F3 differential scanning calorimetry. The heating rate was $10.0^{\circ} \mathrm{C} / \mathrm{min}$ from room temperature to $220^{\circ} \mathrm{C}$; then, cooling was performed at the same rate under the protection of nitrogen. The decomposition behavior was studied with a Netzsch (Erich NETZSCH $\mathrm{GmbH} \&$ Co., Germany) 209F3 thermogravimeter. The heating rate was $20.0^{\circ} \mathrm{C} / \mathrm{min}$ from room temperature to $500^{\circ} \mathrm{C}$ under the protection of nitrogen.

\section{Results and Discussion}

\subsection{The effects of melt index of PP on preparation of powders}

Bulleted lists look like this:In order to study the influence of melt index of different PP on preparation of powder, we use different grades of polypropylene to measure the melt index and prepare powder.

Table I.The effects of melt index of PP on preparation of powders 


\begin{tabular}{ccc}
\hline Grades & Melt index $(\mathbf{g} / \mathbf{1 0 m i n})$ & Experimental result \\
\hline T30S & 6.0 & Sol, hardly possible to separation \\
SA233CF & 8.1 & Sol, hardly possible to separation \\
RP707CF & 8.9 & Small block \\
SD233CF & 10.0 & Small block \\
K3500 & 11.1 & Powdery, difficult to separation \\
HJ730 & 17.8 & Powdery, easy to separation \\
eps30r & 34.0 & Powdery, easy to separation
\end{tabular}

As show in Table I, the grades of polypropylene T30S, SA233CF, RP707CF, SD233CF are impossible to prepare powder with solvent method, the product is sol or small block and it's hardly possible to separation. The grade $\mathrm{K} 3500$ can prepare powder, but the product is difficult to separation and need to add alcohol to extract, so the solvent xylene could not reused directly. The grades of polypropylene HJ730 and eps30r can prepare powder, the products are easy to be separated and after drying it can be milled to powder. The experiment shows that after a low melt index PP dissolved the product is sol or slug, and when a large melt index PP dissolved, the product is powdery and easy to separate. This is because the melt index can influence the surface tension of the powder particles, the lower the melt index, the greater the molecular weight, the agglomeration between PP particles will be more apparent and easier to group together; however, the larger the melt index, the smaller of the molecular weight, which will lead the sintering parts performance of prepared powders to be worse. Therefore, we select the HJ730 as a raw material for the preparation of polypropylene powder, which's melt index is $17.78 \mathrm{~g} / 10 \mathrm{~min}$.

\subsection{The effects of processing temperature on the characteristics of the powder}

Preparation of polypropylene powder with solvent method actually is a process that polymer dissolved by heating, which need to go through three stages: heating, constant temperature, cooling. The processing temperature will influence the dissolution process of the polypropylene resin, which can affect the apparent density and the average particle size of prepared powder. At lower temperature, the resin particles partially dissolved, so the average particle size of powder is large, and the gap between the powder particles will become large when they accumulated be free, and the apparent density will be small; at higher temperature, the resin particles completely dissolved, the average particle size is small, and the internal density will decreased, so the apparent density of the prepared powder will reduce; only at a suitable temperature, most of the resin dissolved, and the remaining undissolved portion acts as a nucleating agent in the crystallization process, so the distribution of average particle size of prepared powder will be suitable and the apparent density of the powder at this time will be relatively large.

The effects of processing temperature on the characteristics of powder is shown in Figure 1, which shows the apparent density and the average particle size of the powder relative to the processing temperature from $160.0{ }^{\circ} \mathrm{C}$ to $185.0{ }^{\circ} \mathrm{C}$, given that the melt index of the raw material is $17.8 \mathrm{~g} / 10 \mathrm{~min}$. As the processing temperature increases from $160.0{ }^{\circ} \mathrm{C}$ to $185.0{ }^{\circ} \mathrm{C}$, the apparent density of the powder increases first, then decreases, and towards stability at last, but the average particle size of the powder dramatically decreases. When the processing temperature is $166.0{ }^{\circ} \mathrm{C}$, the apparent density of the powder is $0.29 \mathrm{~g} / \mathrm{cm} 3$ and the average particle size is $72 \mu \mathrm{m}$. As shown in Figure $5(\mathrm{c})$ and $(\mathrm{d})$, the surface morphology of prepared powder is coarse, and there were many cracks and pores. 


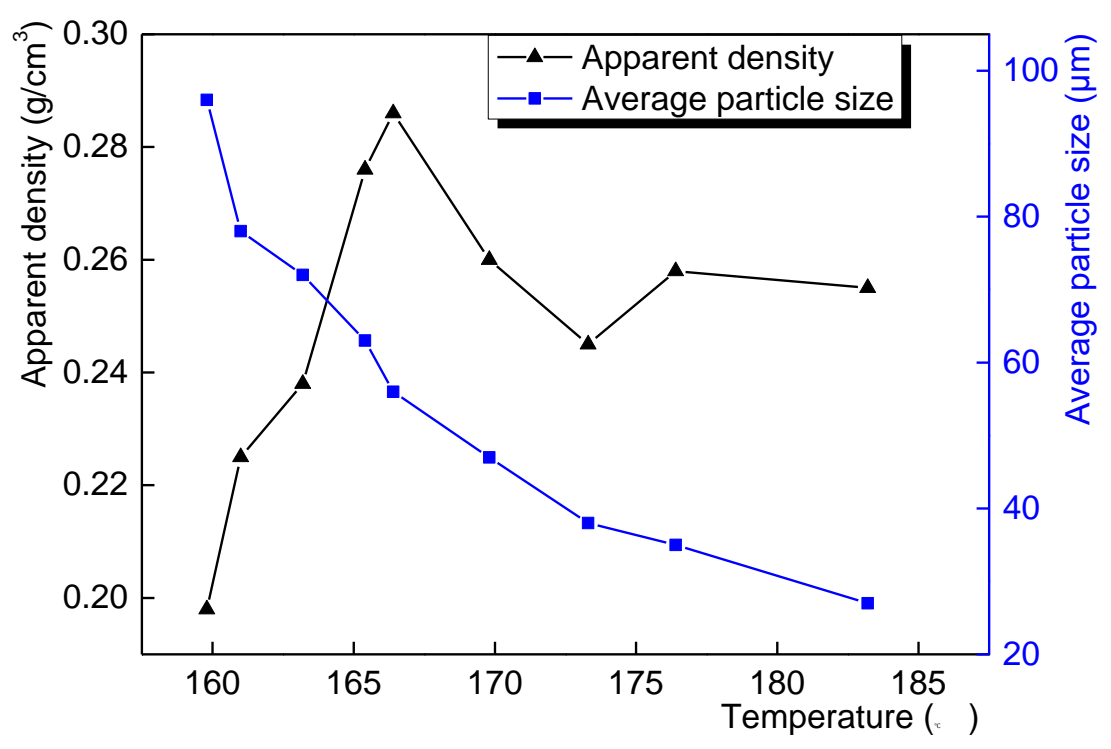

Figure 1.Plots of average particle size diameter and apparent density of polypropylene powders vs processing temperature

\subsection{The effects of dosage of solvent on the characteristics of powder}

The effects of dosage of the solvent on the characteristics of powder is shown in Figure 2, which shows the apparent density and the average particle size of the powder relative to the dosage of solvent from $0.033 \mathrm{~g} / \mathrm{ml}$ to $0.083 \mathrm{~g} / \mathrm{ml}$, given that the melt index of the raw material is $17.8 \mathrm{~g} / 10 \mathrm{~min}$, the processing temperature is $166.0{ }^{\circ} \mathrm{C}$. As the dosage of solvent increases from $0.33 \mathrm{~g} / \mathrm{ml}$ to $0.83 \mathrm{~g} / \mathrm{ml}$, the apparent density of the powder increases first and then decreases, the average particle size of the powder dramatically increases. When the dosage of solvent is $0.067 \mathrm{~g} / \mathrm{ml}$, the apparent density of the powder is $0.37 \mathrm{~g} / \mathrm{cm} 3$ and the average particle size is $65 \mu \mathrm{m}$. As shown in Figure 5 (c) and (d), the surface morphology of prepared powder is smooth, good spherical and there were a small amount of cracks and pores. If continuing to increase the dosage of solvent, the apparent density of the powder will decrease, and the average particle size will increase; if the dosage of solvent reduced, the average particle size of the prepared powder can be reduced, but the amount of xylene in the unit mass of prepared powder will increase, which will improve the production cost.

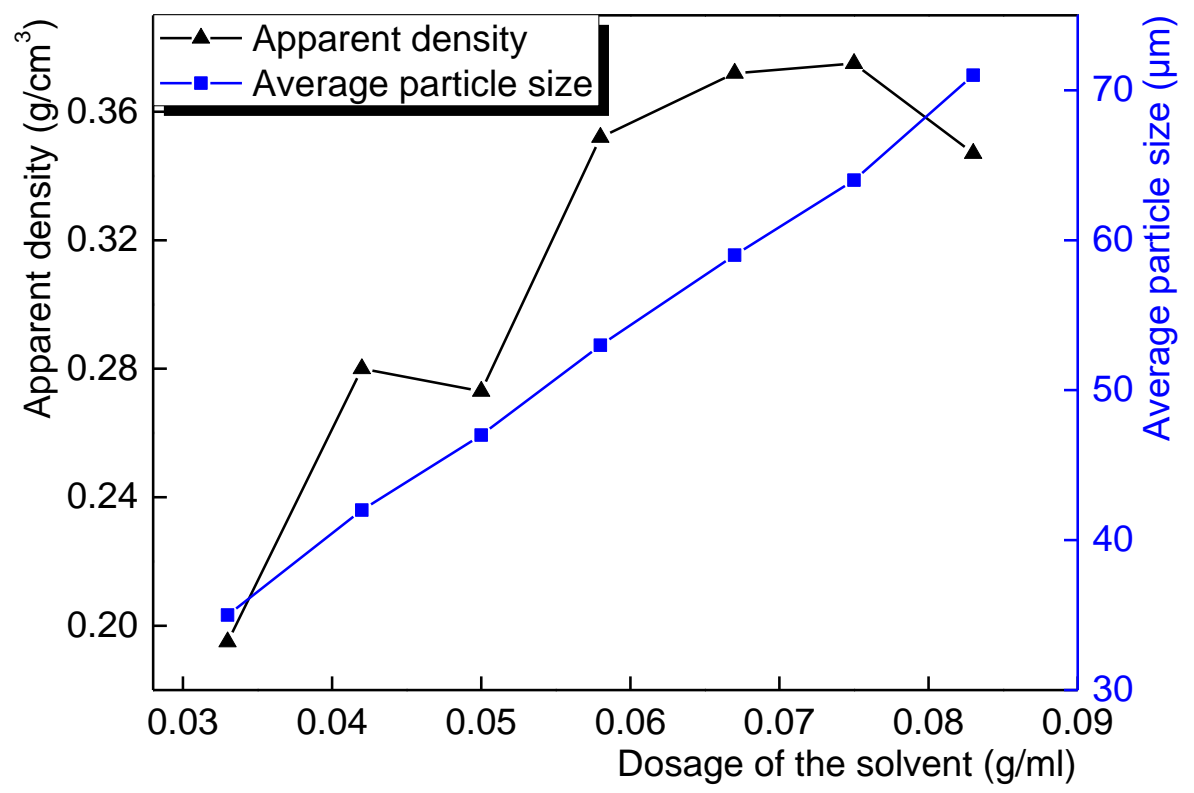

Figure 2. Plots of average particle size diameter and apparent density of polypropylene powders vs dosage of solvent 


\subsection{The effects of packing pressure on the characteristics of powder}

The effects of packing pressure on the characteristics of powder is shown in Figure 3, which shows the apparent density and the average particle size of the powder relative to the packing pressure from $0 \mathrm{MPa}$ to $1.1 \mathrm{MPa}$, given that the melt index of the raw material is $17.8 \mathrm{~g} / 10 \mathrm{~min}$, the processing temperature is $166.0{ }^{\circ} \mathrm{C}$, and the dosage of solvent is $0.067 \mathrm{~g} / \mathrm{ml}$. As the packing pressure increases from $0 \mathrm{MPa}$ to $1.1 \mathrm{MPa}$, the apparent density of the powder increases first and then towards stability, the average particle size of the powder dramatically decreases. When the packing pressure is $0.7 \mathrm{MPa}$, the apparent density of the powder is $0.40 \mathrm{~g} / \mathrm{cm} 3$ and the average particle size is $42 \mu \mathrm{m}$. As shown in Figure 5 (e) and (f), the surface morphology of prepared powder is very smooth, good spherical and there were only a few of cracks and pores, which is consistent with the requirement of selective laser sintering for powder materials. And excessive pressure will increase the cost of the preparation process, and also less secure, so the packing pressure chosen 0.7MPa.

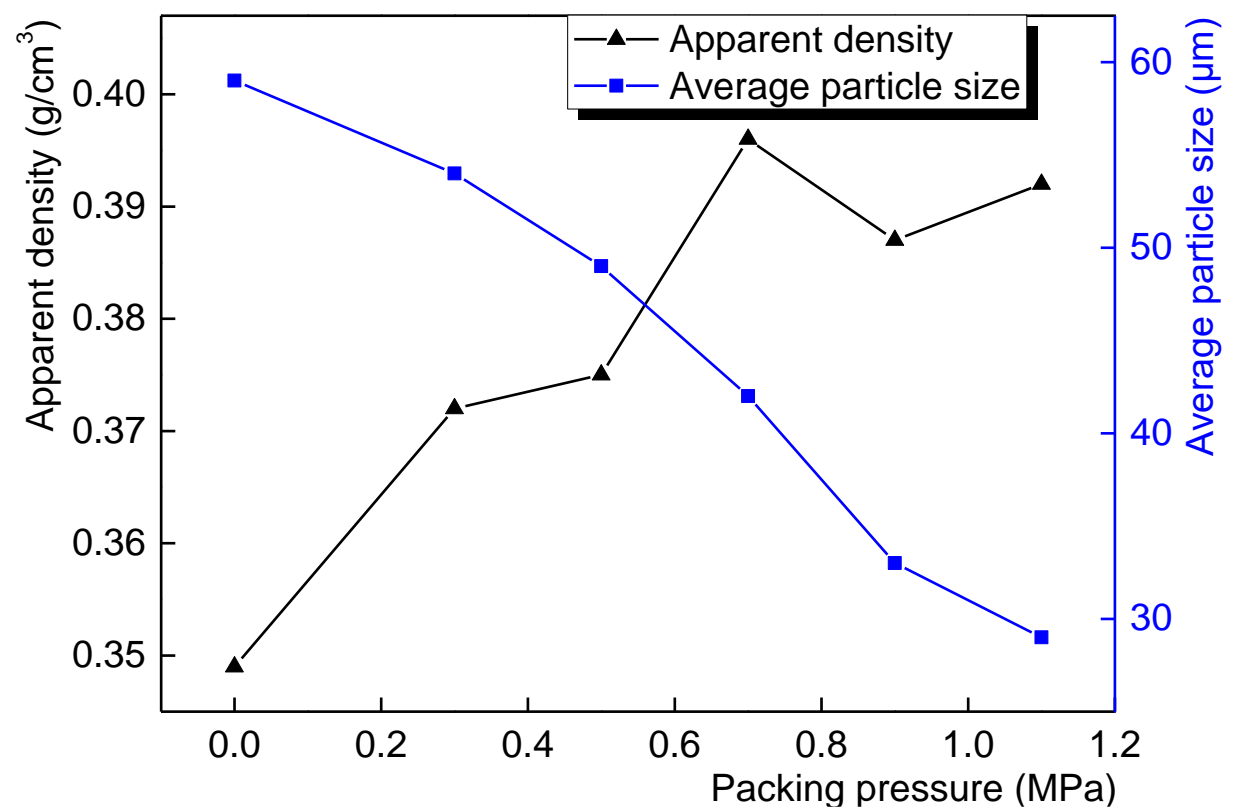

Figure 3. Plots of average particle size diameter and apparent density of polypropylene powders vs packing pressure

\subsection{Characteristics of the powder}

A proper particle diameter and distribution are necessary for SLS. In previous studies, a particle diameter of $20 \sim 60 \mu \mathrm{m}$ was found to be ideal. If it is smaller than $20 \mu \mathrm{m}$, spreading the powder becomes difficult; if it is larger than $60 \mu \mathrm{m}$, the precision of the SLS parts and sintering characteristics deteriorate. Figure 4 shows the particle diameter distribution curves of polypropylene powders prepared on different conditions. According to Figure 4(a), the average diameter of the powders prepared on $166.0{ }^{\circ} \mathrm{C}$ was $72 \mu \mathrm{m}$, and the distribution was wide; only $20.0 \%$ of the particles were smaller than $60 \mu \mathrm{m}$, most larger than $60 \mu \mathrm{m}$. The powders prepared on $166.0{ }^{\circ} \mathrm{C}$ and the dosage of solvent is $0.067 \mathrm{~g} / \mathrm{ml}$ are shown in Figure 4(b), the average diameter was $65 \mu \mathrm{m}$, about $50.8 \%$ of the particles were smaller than $60 \mu \mathrm{m}$. The powders prepared on $166.0{ }^{\circ} \mathrm{C}$, the dosage of solvent is 0.067 $\mathrm{g} / \mathrm{ml}$ and the packing pressure is $0.7 \mathrm{MPa}$ exhibited a narrow particle diameter distribution, as shown in Figure 4(c), with an average particle diameter of $42 \mu \mathrm{m} .2 .0 \%$ of the particles were smaller than 20 $\mu \mathrm{m}$, and $6.0 \%$ were larger than $60 \mu \mathrm{m}$. 


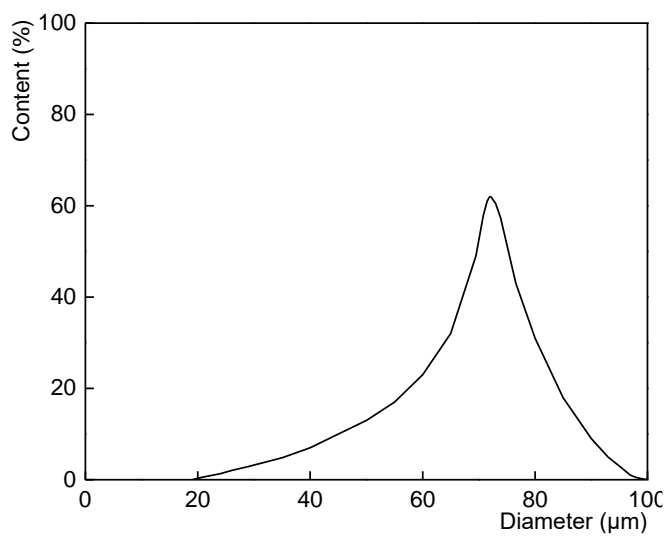

(a)

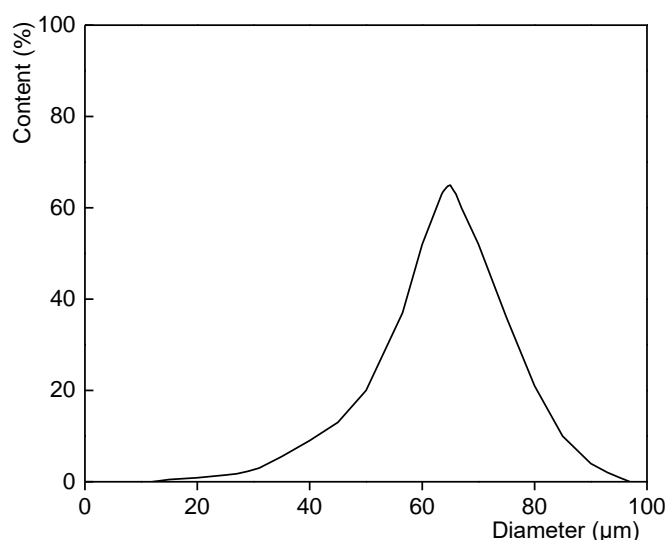

(b)

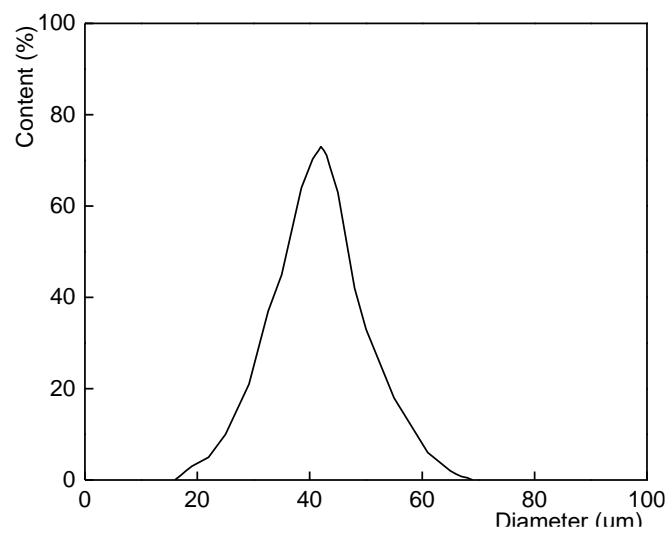

(c)

Figure 4. Particle diameter distribution curves of polypropylene powders prepared on different conditions: (a)processing temperature $166.0^{\circ} \mathrm{C}$;(b) processing temperature $166.0^{\circ} \mathrm{C}$ and dosage of solvent $0.067 \mathrm{~g} / \mathrm{ml}$; (c) processing temperature $166.0^{\circ} \mathrm{C}$, dosage of solvent $0.067 \mathrm{~g} / \mathrm{ml}$ and packing pressure $0.7 \mathrm{MPa}$.

\subsection{Morphology of the powder surface}

Scanning electron microscopy (SEM) images of powders prepared on different conditions are shown in Figure 5. According to the comparison of (a), (c), (e) and (b), (d), (f), we can know that the preparation conditions have great influence on the morphology of the powders. By changing the conditions, the particle size become smaller, the distribution become narrow and the surface turn into smoother, there were fewer cracks and pores. 


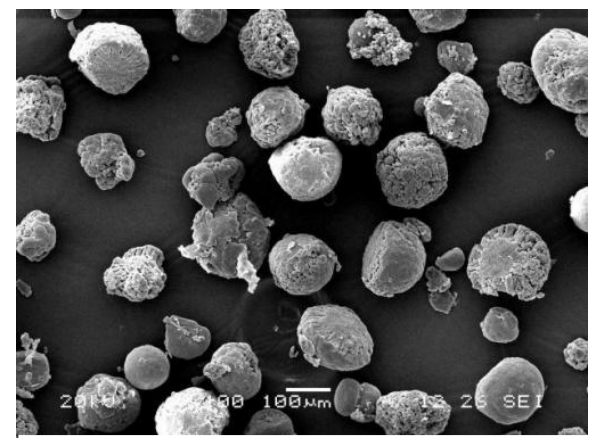

(a)

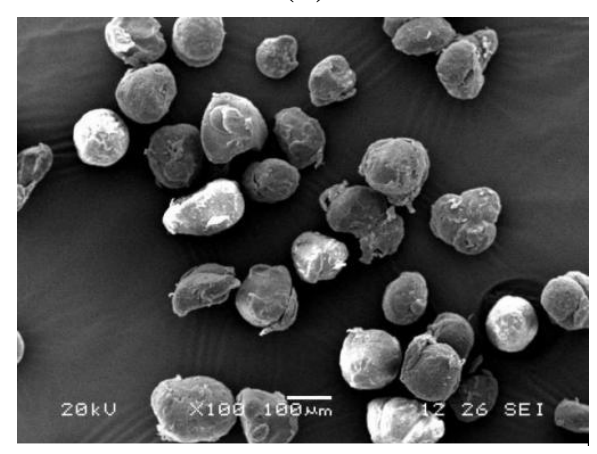

(c)

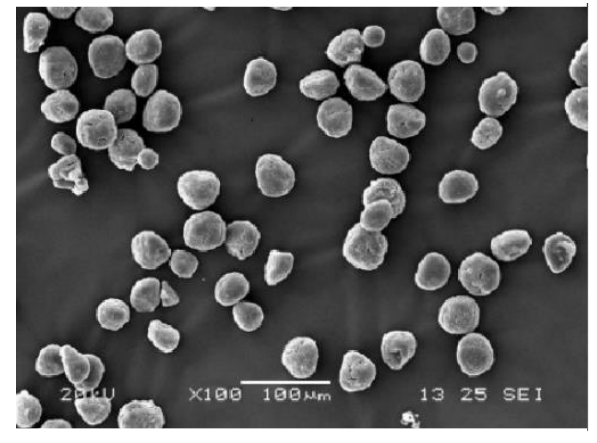

(e)

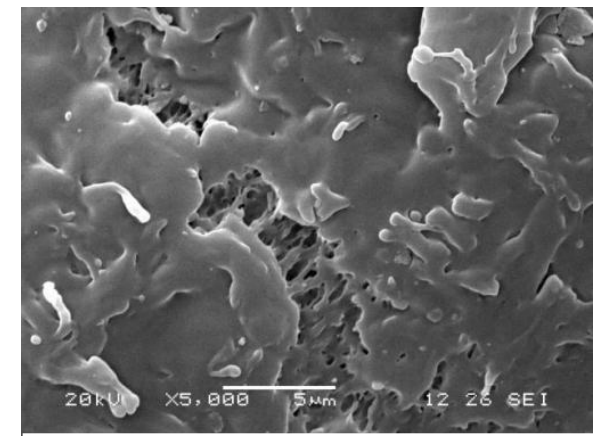

(b)

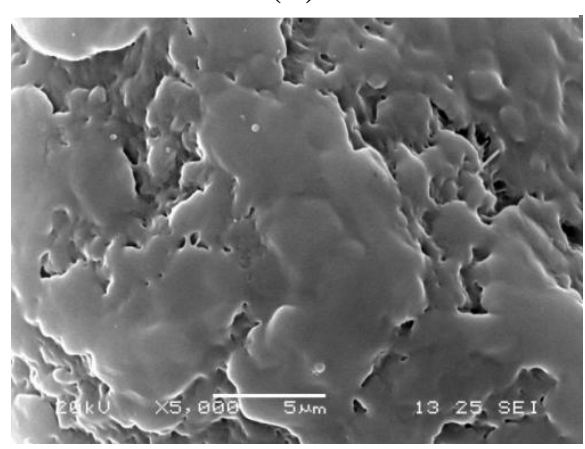

(d)

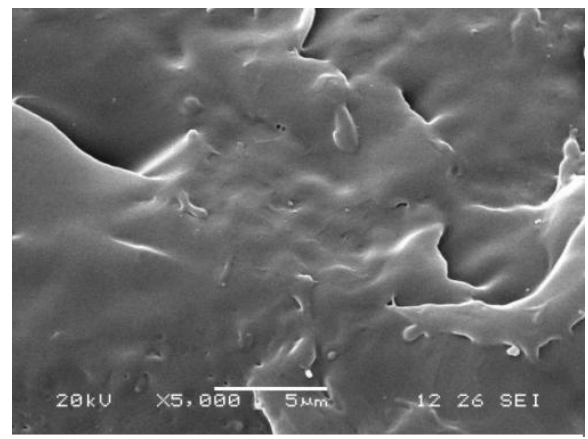

(f)

Figure 5. SEM micrographs showing the surface of polypropylene powders prepared on different conditions: (a,b)processing temperature $166.0^{\circ} \mathrm{C} ;(\mathrm{c}, \mathrm{d})$ processing temperature $166.0^{\circ} \mathrm{C}$ and dosage of solvent $0.067 \mathrm{~g} / \mathrm{ml} ;(\mathrm{e}, \mathrm{f})$ processing temperature $166.0^{\circ} \mathrm{C}$, dosage of solvent $0.067 \mathrm{~g} / \mathrm{ml}$ and packing pressure $0.7 \mathrm{MPa}$.

\subsection{Thermal properties}

DSC measurements are performed to study the thermal behavior, suitability, and processing behavior of polypropylene powders. The result of the DSC test for the polypropylene powders prepared on $0.7 \mathrm{MPa}, 166.0^{\circ} \mathrm{C}$ and the dosage of solvent is $0.067 \mathrm{~g} / \mathrm{ml}$ is illustrated in Figure 6 . From the heating curves, we can observe that there has one peak, the polypropylene powders began to melt at $177.1{ }^{\circ} \mathrm{C}$, and ended at $185.9{ }^{\circ} \mathrm{C}$, the melting point is $182.3{ }^{\circ} \mathrm{C}$; by comparing the cooling curves, we can obtained the crystallization process of the polypropylene powders, it begins at $151.3{ }^{\circ} \mathrm{C}$ and ends at $157.6{ }^{\circ} \mathrm{C}$, the crystallization temperature was $154.5{ }^{\circ} \mathrm{C}$. Theoretically, the sintering temperature window is the range of temperatures within which the polymer powder begins to melt and the melt begins to crystallize. The theoretical sintering temperature window $(\Delta \mathrm{T} 0)$ can be calculated with the flowing equation:

$$
\Delta \mathrm{T} 0=\operatorname{Tim}-\mathrm{Tic}(1)
$$


Where Tim is the initial melting temperature, Tic is the finished crystallization temperature. Form the analysis of DSC result, we can know the available sintering window of the polypropylene powders is from $157.6 \sim 177.1{ }^{\circ} \mathrm{C}$, and it's large enough for SLS.

Figure 7 shows the thermogravimetry (TG) curves of the polypropylene powders prepared on $0.7 \mathrm{MPa}, 166.0^{\circ} \mathrm{C}$ and the dosage of solvent is $0.067 \mathrm{~g} / \mathrm{ml}$. The initial degradation temperature was $323.4{ }^{\circ} \mathrm{C}$. The decomposition temperature for 20 percent weight loss of the powder is $389.8^{\circ} \mathrm{C}$ and the $99.26 \%$ mass loss for the powder at $459.2{ }^{\circ} \mathrm{C}$.

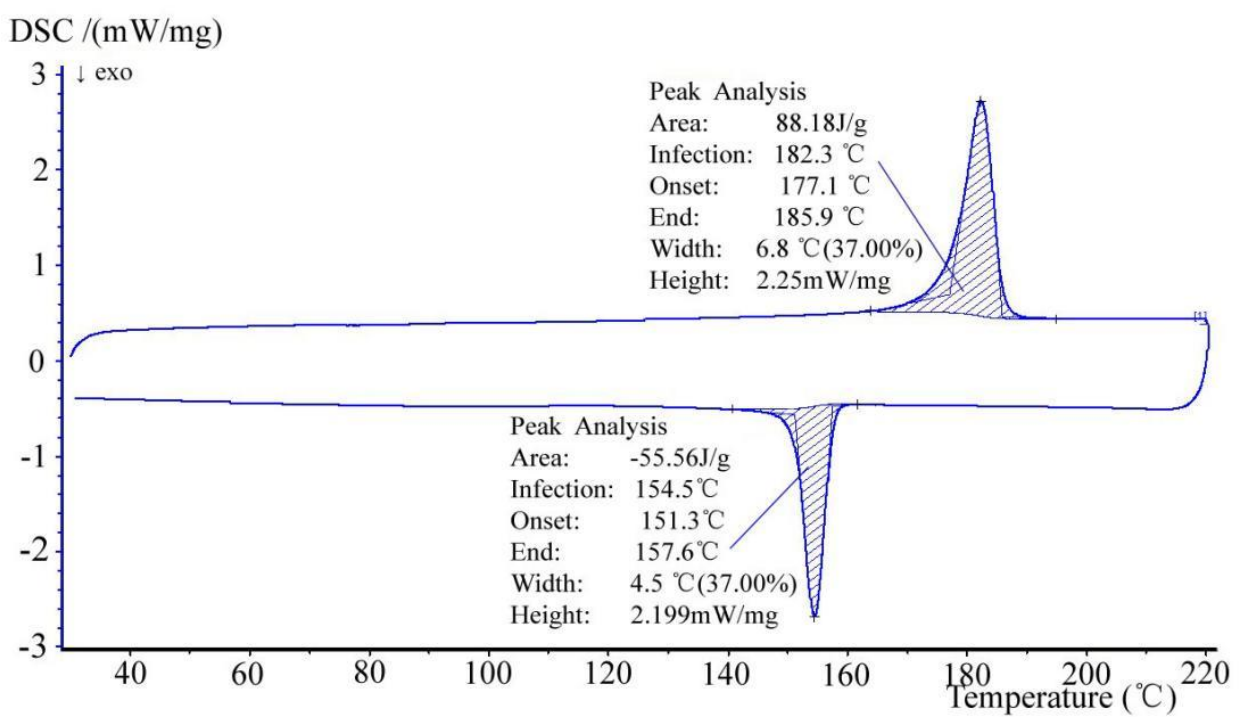

Figure 6. DSC result of polypropylene powders prepared $0.7 \mathrm{MPa}, 166.0^{\circ} \mathrm{C}$ and the dosage of solvent is $0.067 \mathrm{~g} / \mathrm{ml}$

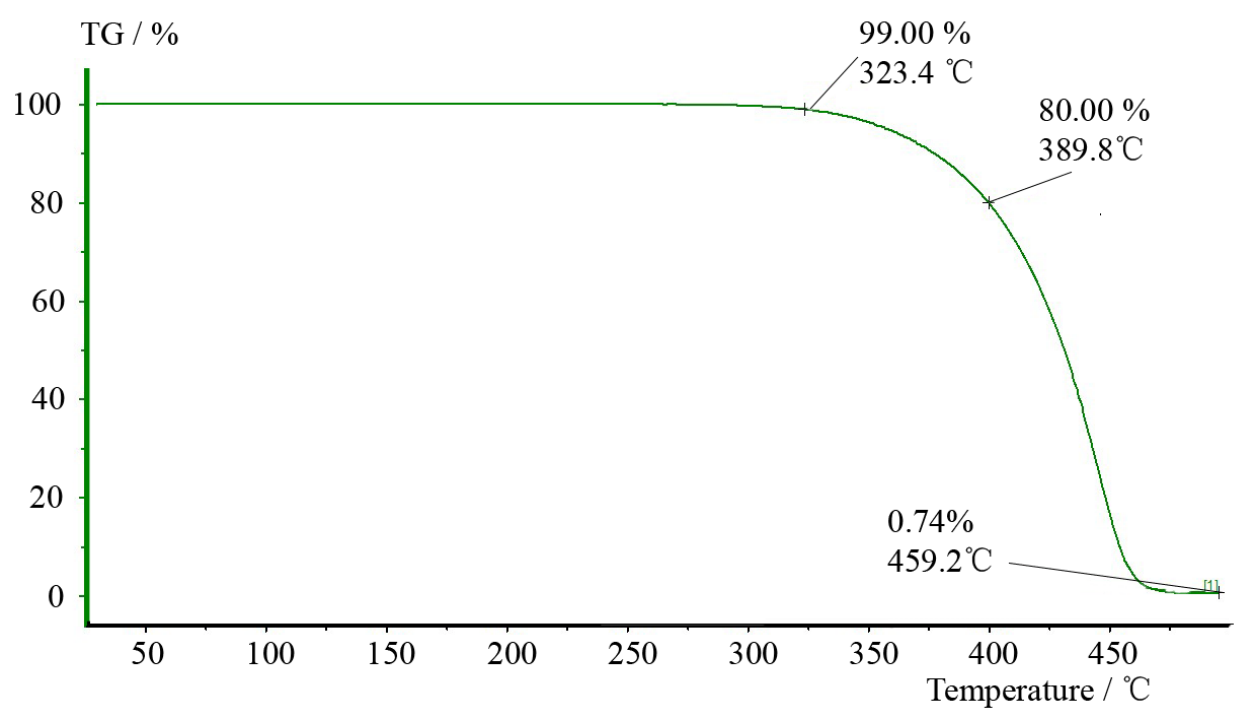

Figure 7. TG curves of polypropylene powders prepared $0.7 \mathrm{MPa}, 166.0^{\circ} \mathrm{C}$ and the dosage of solvent is $0.067 \mathrm{~g} / \mathrm{ml}$

\section{Conclusions}

A dissolution-precipitation process has been a good method to produce PP powders for applications in SLS. This research uses different melt index polypropylene as raw materials to produce powders, also, the influences of processing temperature, dosage of the solvent and packing pressure are examined.

By experimenting different conditions, the optimal technological conditions are: processing temperature being about $166.0{ }^{\circ} \mathrm{C}$, dosage of the solvent being about $0.067 \mathrm{~g} / \mathrm{ml}$ and the packing 
pressure being about 0.7 MPa. Under this technological conditions, the apparent density of the powders can reach $0.40 \mathrm{~g} / \mathrm{cm} 3$, the particle diameter distribution is narrow and the average particle diameter is $42 \mu \mathrm{m}$, the surface morphology of prepared powder is very smooth, good spherical and there were only a few of cracks and pores, which is consistent with the requirement of selective laser sintering.

Author Contributions: Liang Fang conceived, designed and performed the experiments; Yang Xu contributed reagents/materials/analysis tools; Yan Wang and Yang $\mathrm{Xu}$ wrote the paper.

Funding: This research received no external funding.

\section{Acknowledgments:}

Conflicts of Interest: The authors declare no conflict of interest.

\section{References}

1. Wei Zhu, Chunze Yan, Yunsong Shi. Investigation into mechanical and microstructural properties of polypropylene manufactured by selective laser sintering in comparison with injection molding counterparts [J]. Materials and Design, 2015, 1-36.

2. Hopkinson N, Hague RJM, Dickens PM. Rapid Manufacturing: An Industrial Revolution fortheDigital Age, John Wiley, England, 2006.

3. Jinsong Yang, Yusheng Shi, Chunze Yan. Selecive Laser Sintering of Polyamide 12/Potassium Titanium Whisker COmposites[J]. Journal of Applied Polymer Science, 2010, 2196-2204.

4. Seyed Farid Seyed Shirazi, Samira Gharehkhani, Mehdi Mehrali. A review on powder-based additivemanufacturing for tissue engineering:selective laser sintering and inkjet 3Dprinting[J]. Science and Technology of Advanced Materials, 2015, 1-20.

5. Kühnlein, F., Rietzel, D., Wendel, B., Feulner,Hülder, G., Schmachtenberg, E. Plastverarbeiter, 08 (2008).

6. M. A. Beard, O. R. Ghita, K. E. Evans. Monitoring the Effects of Selective Laser Sintering (SLS)Build Parameters on Polyamide Using Near InfraredSpectroscopy[J]. Journal of Applied Polymer Science, 2011, 3153-3158.

7. D. Rietzel, F. Kuehnlein, D. Drummer. Characterization of new thermoplastics for additive manufacturing by Selective Laser Sintering. 2010, 2247-2253.

8. Eshraghi S and Das S. Mechanical andmicrostructural properties of polycaprolactone scaffolds with onedimensional, two-dimensional, and threedimensional orthogonally oriented porous architecturesproduced by selective laser sintering Acta Biomater. 2010,67-76.

9. Vaezi M, Seitz H and Yang S. A review on 3D microadditive manufacturing technologies[J]. Int. J. Adv. Manuf.Technol. 2013, 21-54

10. Kruth J-P, Kumar S and Van Vaerenbergh J. Study oflaser-sinterability of ferro-based powders Rapid Prototyping[J]. 2005,87-92.

11. Sachdeva A, Singh S and Sharma V. Investigatingsurface roughness of parts produced by SLS process[J]. Int. J.Adv. Manuf. Technol. 2013, 05-16

12. Goodridge R D, Tuck C J,Hague R J M.Laser sintering of polyamides and other polymers[J]. ProgMater Sci, 2012, 229-267. 
13. Rietzel, D., Kühnlein, F., Feulner, R., Hülder, G., vonWilmowsky, C., Fruth, C., Nkenke, E.,Schmachtenberg, E., Proceedings SPE-European Conference onMedical Polymers 2008, Belfast, UK, (2008).

14. Yoshitsugu Kojima, Takaaki Matuoka, Hideroh Takahashi. Preparation of Nylon 66/Mesoporous Molecular Sieve Composite Under High Pressure[J]. Journal of Applied Polymer Science, 1999, 3254-3258.

15. Rault, F., Pleyber, E., Campagne, C., Rochery, M.Effect of manganese nanoparticles on the mechanical, thermal and fire properties of polypropylene multifilament yarn[J]. Polymer Degrada- tion and Stability, 2009, 955-964.

16. Hegde, Raghavendra R., Bhat, Gajanan S.Nanoparticle effects on structure and properties of polypropylene meltblown webs[J]. Journal of Applied Polymer Science, 2010, 1062-1072.

17. Chu, J., Xiang, C., Sue, H.-J., Hollis, R. Damon. Scratch resistance of mineral-filled polypro- pylene materials[J]. Polymer Engineering and Science, 2000, 944-955.

18. Ito K, Mineura K, Yoshikawa C. Development of Ammonia- Ethane Cascade Cooling System forRecycling Used Tires and Plastics[J]. Eighth International Refrigeration Conference at Purdue University, 2000, 25-28.

19. Yusheng Shi, Chunze Yan,Wei Zhu, Yi Fu. The application and peparation of Selective Laser Sintering polypropylene powders material[P].Guangdong Silver Age Sci \& Tech. Co., Ltd., 2014.

20. Yoshitsugu Kojima, Takaaki Matsuoka, Hideroh Takahashi. Preparation of Nylon 66/Mesoporous Molecular Sieve Composite Under High Pressure[J]. Journal of Applied Polymer Science, 1999, 3254-3258.

21. Huang J, Rodrigue D. The effect of carbon nanotube orientation and content on the mechanicalproperties of polypropylene based composites[J]. Mater. Des, 2014, 653-663. 